\title{
MENANAMKAN PENDIDIKAN KARAKTER MELALUI MEDIA AUGMENTED REALITY ANIMASI DUA DIMENSI LAKON DEWA RUCI KEPADA REMAJA
}

\author{
Dwiki Setya Prayoga, I Nyoman Lodra, Autar Abdillah \\ Program Pascasarjana, S-2 Pendidikan Seni Budaya \\ Universitas Negeri Surabaya \\ Jalan Lidah Wetan, Surabaya \\ No.Hp.:081334088982,E-mail: dwikiprayoga255@gmail.com
}

\begin{abstract}
ABSTRAK
Remaja merupakan generasi penerus bagi bangsa dan negara. Namun, remaja juga berpotensi mempunyai perilaku buruk dan di luar kendali yang dapat mengancam bangsa dan negara, seperti perkelahian, kekerasan, penyalahgunaan narkoba, minuman keras, dan seks bebas. Sangat penting untuk menanamkan nilai-nilai pendidikan karakter kepada remaja seperti kejujuran, saling menghormati, sopan santun, dan pantang menyerah. Pendidikan karakter sering dikaitkan dengan kebudayaan yang berhubungan dengan budi dan akal manusia. Hidup manusia tidak lepas dari kebudayaan dan adat istiadat. Salah satu contoh kebudayaan adalah wayang. Wayang merupakan simbol manusia dan bayangan dari kemanusiaan itu sendiri. Lakon Dewa Ruci bercerita tentang murid yang patuh kepada gurunya. Sebagai murid hendaknya menghormati gurunya, sedangkan guru hendaknya tegas dan sabar dalam menghadapi muridnya. Guru dalam dunia pendidikan dituntut untuk meningkatkan kualitas dan mutunya. Dalam upaya mencerdaskan kehidupan bangsa, peranan teknologi sangat diperlukan supaya remaja memiliki wawasan yang luas serta dapat memiliki minat dan ketertarikan untuk terus tetap belajar. Saat ini video animasi seringkali digemari oleh remaja umumnya apalagi dalam dunia pendidikan. Animasi digunakan sebagai media atau alat untuk menyampaikan informasi yang lebih terkini. Evaluasi yang dilakukan dalam animasi ini menggunakan angket dan diperoleh hasil uji kualitas media aspek materi mendapatkan hasil $98 \%$ dan pada post test mendapatkan hasil $63 \%$. Dari data angket tersebut dapat dikatakan produk ini layak dan tidak perlu direvisi.
\end{abstract}

Kata kunci: pendidikan karakter, animasi dua dimensi, Dewa Ruci, remaja

\section{ABSTRACT}

Implanting Character Education Values through the Augmented Reality of TwoDimensional Animation of Dewa Ruci to Teenagers. Teenagers are the next generation for the nation and country. However, teenagers tend to have bad behaviors and act out of control that can threat the nation and the country, such as being involved in a fight, violence, drug abuse, alcohol addict, and even free sex. It is very important to instill the values of character education to the teenagers such as honesty, mutual respect, courtesy, and perseverance. Character education is often related to culture with regards to the mind and common senses. This is because human's life cannot be separated from culture and the traditions. One of the cultural things is wayang (shadow puppetry). Shadow puppetry is a symbol of human beings and the shadow of their humanity. Lakon Dewa Ruci (Dewa Ruci play) tells a story of a student who is obedient to his teacher. As implied in the story, a student is supposed to be obedient to his teacher, while the teacher must be discipline yet patient in dealing with the students. A teacher with his responsibility in education is demanded to enhance his quality and his expertise. In the effort to educate the life of a nation, the role of technology is need 
in order to make the teenagers have a broader knowledge as well as to have an interest and a passion to keep learning. Nowadays animated videos are often preferred by the teenagers in general, not to mention in the field of education. Animation has become media or instruments to deliver the most updated information. Evaluation conducted in this research had used a questioner and the result showed $98 \%$ for the media quality from the material aspects and for the post test obtained $63 \%$. Therefore, the results could define whether this product of animation is eligible, or in other words, no revision is needed.

Keywords: character education, two dimensional animation, Dewa Ruci, teenagers

\section{PENDAHULUAN}

Remaja merupakan generasi penerus bangsa dan negara. Namun, remaja juga berpotensi mempunyai perilaku buruk dan di luar kendali yang dapat mengancam bangsa dan negara seperti perkelahian, kekerasan, dan penyalahgunaan narkoba. Sangat penting untuk menanamkan pendidikan karakter kepada remaja seperti kejujuran, saling menghormati, sopan santun, dan pantang menyerah. Pendidikan karakter sering dikaitkan dengan kebudayaan yang berhubungan dengan budi dan akal manusia. Kehidupan manusia tidak lepas dari kebudayaan dan adat istiadat setempat.

Fenomena kenakalan remaja di Indonesia terkait dengan pada usia ini remaja mengalami proses pembentukan diri menjadi dewasa. Masa yang penuh dengan pengaruh untuk melalui tahap masa dewasa. Dengan demikian, benturanbenturan sering terjadi pada masa remaja, banyak persoalan yang dihadapi secara mental, jiwa, dan rohaninya sehingga menimbulkan perilaku atau tindakan yang menyimpang dan kriminalitas (Lestari, 2012). Terlebih zaman sekarang ini yang sangat mudah dan cepat dipengaruhi oleh globalisasi ketika arus atau sumber informasi begitu mudah dan cepat didapatkan. Remaja yang terlahir pada zaman ini dengan kemajuan iptek yang sekarang dapat terpengaruh bahkan terprovokasi tindakan- tindakan di luar batas norma-norma yang berlaku (Pratiwi \& Surahman, 2019).

Pendidikankarakterseringdikaitkandengan kebudayaan dan kebudayaan berhubungan dengan akal dan budi manusia. Salah satunya adalah kebudayaan wayang. Wayang merupakan simbol manusia dan bayangan dari kemanusiaan itu sendiri. Cerita wayang dari segi sastra dan tokoh mempunyai nilai filosofi yang tinggi dalam menghadapi kehidupan zaman saat ini (Mulyono, 1982). Wayang juga sangat dekat dengan manusia sehingga wayang sebagai simbol atau memperadabkan manusia itu sendiri. Misalnya lakon Dewa Ruci bercerita tentang murid yang patuh kepada gurunya, pesan moral pada umumnya sebagai murid hendak menghormati guru, sedangkan guru hendak tegas dan sabar dalam menghadapi murid. Lakon Dewa Ruci digambarkan sebagai seorang murid yang hormat dan patuh terhadap gurunya, yang mengajarkan dan memberi ilmu dalam kehidupan seperti kemandirian, jati diri, dan pantang menyerah banyak petuah bijak tentang kehidupan dalam lakon tersebut (Setiawan, 2017).

Hidup di bidang pendidikan harus mampu berperan aktif menyiapkan sumber daya maju dan unggul di berbagai bidang dan cabang keilmuan. Peserta didik harus mampu mengatasi dan memecahkan berbagai 
persoalan tantangan hidup. Selain itu, peserta didik juga mampu menerapkan ilmu yang didapat dalam kehidupan sehari-hari (Suyitno, 2012). Pendidikan karakter tidak lepas dari kebudayaan, seperti wayang yang merupakan budaya dan tradisi turut berperan aktif dalam pembentukan karakter karena wayang dan teknologi saat ini digunakan sebagai media pendidikan (Nurgiyantoro, 2011).

Identitas berarti sebuah gambaran diri yang memiliki nilai, tujuan dan kepercayaan, pendekatan dalam identitas diri erat hubungannya dengan kehidupan dan lingkungan sosialnya (Sadewa, 2019). Video animasi lakon Dewa Ruci secara filosofis melambangkan manusia harus menjalani perjalanan batin untuk menemukan identitas dirinya atau sering disebut sangkan paraning dumadi yang berarti "dari mana manusia berasal dan akan ke mana ia akan kembali”. Media video merupakan karya seni yang dapat dibaca, didengar, dan ditonton untuk menarik perhatian audiens (remaja).

Pemanfaatan teknologi dalam proses penyampaian informasi mengalami perkembangan pesat. Animasi dua dimensi dapat dikombinasikan dengan augmented reality yang dapat memvisualisasikan objek ke bentuk nyata (Haryani \& Triyono, 2017). Selain itu, dengan teknologi tersebut dapat dengan mudah meningkatkan pemahamann peserta didik karena berupa objek dua dimensi: visual dan audio. Melalui media ini peserta didik akan mendapat feedback atau informasi berupa ilmu pendidikan karakter dalam video animasi lakon Dewa Ruci (Abdoli-Sejzi \& Bahru, 2015).

Animasi lakon Dewa Ruci merupakan transformasi bentuk, pemindahan realitas dari wayang yang digerakkan oleh dalang ke bentuk gambar wayang digital (vektor) yang digerakkan oleh animator. Namun, sampai batas terjauh transformasi animasi tidak mengubah sisi dalam atau ruh, termasuk sifat dan karakter objek (Saidi, 2017). Animasi sangat besar fungsi, kegunaan, dan manfaatnya untuk kebutuhan mengajar dan proses penyampaian informasi. Bahkan bercerita tentang realita kehidupan yang terkadang sulit untuk dijelaskan secara naratif, tetapi sangat sering diungkapkan dengan bentuk gambar yang bergerak (Prakosa, 2010).

Penggabungan antara animasi dan lakon Dewa Ruci merupakan bentuk proses untuk menyampaikan pendidikan karakter kepada remaja sehingga informasi-informasi ini perlu dirancang agar dapat menyampaikan pesan penting seperti apa pendidikan karakter yang akan ditampilkan. Dalam video animasi secara umum bukan hanya berbicara bagaimana pergerakan-pergerakan yang dilakukan, tetapi lebih banyak hal yang harus dikerjakan untuk menunjang penganimasian (Ruslan, 2016). Misalnya cerita, ide, atau konsep meliputi karakter, background, dan background musik yang diusung. Kemudian bagaimana bentuk animasi lakon Dewa Ruci, bagaimana kualitas animasi lakon Dewa Ruci, dan bagaimana keefektifan animasi lakon Dewa Ruci, melalui beberapa tahap metode, beberapa responden dan beberapa validator akan diuji terhadap produk tersebut.

\section{PEMBAHASAN}

\section{Hasil Penelitian}

Dalam penelitian ini digunakan research \& development dengan pendekatan kualitatif dan kuantitatif yang terdiri atas observasi, wawancara, studi pustaka, dan angket kuesioner (Sugiyono, 2013). Model pengembangan yang digunakan adalah 4D, yaitu define, design, develop, dan disseminate. 
Define, melalui tahap observasi ditemukan kurangnya pemahaman serta pengetahuan tentang Dewa Ruci pada remaja. Karakter atau desain yang digunakan menyerupai wayang agar tetap mengingatkan remaja pada kebudayaan seni pertunjukan wayang pada umumnya. Remaja akan dapat dengan mudah memahami tokoh-tokoh yang terlibat dalam lakon Dewa Ruci.

Design, melalui tahap analisis remaja saat ini yang dipengaruhi oleh lingkungan sekitar, maka diperlukan pendidikan karakter. Misalnya rasa hormat, yang menunjukkan rasa menghargai diri orang lain yang lebih tua usianya. Sikap toleransi yang harus diwujudkan dalam berbangsa dan bernegara karena Indonesia merupakan negara majemuk. Konsep religius diangkat dalam animasi lakon Dewa Ruci, sosok Bima yang religius juga lemah lembut dan sabar. Bima selalu berpikir positif dengan kejadian apa pun yang menimpanya.

Develop, melalui tahap ahli desain. Produk awal yang digunakan adalah sebuah tempat pensil dari kardus tebal, setelah melalui tahap uji coba dan evaluasi produk akhir berbentuk pop up card.

Disseminate, tahap ini dilaksanakan dua tahap pertama pretest dan kedua post test. Tujuannya adalah untuk mengetahui seberapa tingkat pemahaman serta sikap dan perilaku remaja saat ini.

\section{Teknik Pengumpulan Data}

Untuk mendapatkan data yang akurat dan kredibel, dalam penelitian ini digunakan beberapa teknik pengumpulan data. Beberapa tahap yang dilakukan dalam mengumpulkan data adalah sebagai berikut.

Observasi

Observasi dan wawancara dilakukan di kediaman salah satu dalang di Jawa
Timur bernama Ki Surono Gondo Taruno. Mengumpulkan catatan berupa buku dan bercerita langsung mengenai lakon Dewa Ruci, beberapa rekaman video serta CD/DVD.

Wawancara

Wawancara dilakukan kepada salah satu dalang, Ki Surono Gondo Taruna. Ia mengungkapkan bahwa Bima mendapatkan ilmu kesempurnaan hidup dari gurunya, Resi Durna. Menurutnya, manusia memiliki empat nafsu yang wajib dikendalikan, yaitu aluamah, amarah, mutmainah, dan sufiah.

Studi Pustaka

Berupa buku, terdapat tiga buku yang digunakan sebagai acuan: (1) Serial Novel Wayang Spiritual berjudul Dewa Ruci karangan Heru HS.; (2) Sunan Kalijaga karangan Yudi Hadinata; dan (3) Ilmu Kasampurnaan Mengkaji Serat Dewa Ruci karangan Purwadi. Buku tersebut digunakan untuk membuat konsep dan skenario lakon Dewa Ruci.

Angket atau Kuesioner

Digunakan untuk memperoleh informasi dari responden. Menghasilkan data yang berguna untuk mengetahui keefektifan dari animasi lakon Dewa Ruci pada usia 15-18 tahun (remaja). Angket atau kuesioner akan diukur validitas dan reabilitas datanya untuk mendapatkan data yang valid dan realible (Sugiyono, 2013).

\section{Teknik Analisis Data}

Data kuantitatif digunakan untuk menganalisis hasil validasi bentuk, kualitas, dan keefektifan. Data kuantitatif dijelaskan dengan angka berdasarkan hasil penilaian yang dilakukan validator dan responden menggunakan skala Likert. 
Tabel 1 Skala Likert.

\begin{tabular}{cc}
\hline Skala Nilai & Pernyataan \\
\hline 5 & Sangat Baik \\
4 & Baik \\
3 & Cukup Baik \\
2 & Kurang Baik \\
\hline 1 & Tidak Baik \\
\hline
\end{tabular}

Tabel 2 Persentase Skala Likert.

\begin{tabular}{cc}
\hline Persentase & Kategori \\
\hline 5 & Sangat Baik \\
4 & Baik \\
3 & Cukup Baik \\
2 & Kurang Baik \\
\hline 1 & Tidak Baik \\
\hline
\end{tabular}

Kriteria penilaian skala Likert:

Skala Nilai 5: Sangat Baik - Sangat layak digunakan tanpa revisi

Skala Nilai 4: Baik - Layak digunakan tanpa tanpa revisi

Skala Nilai 3: Cukup Baik - Cukup layak digunakan sedikit revisi

Skala Nilai 2: Kurang Baik - Kurang layak digunakan banyak revisi

Skala Nilai 1: Tidak Baik - Belum layak digunakan

Analisis validitas animasi lakon Dewa Ruci berdasarkan kriteria dan persentase tersebut. Analisis validitas produk ini dinyatakan baik jika memiliki persentase $>61 \%$. Skala persentase untuk menentukan kevalidan produk ini menggunakan rumus dalam gambar 1 . Jumlah skor hasil validasi adalah jumlah skor berdasarkan skala Likert dari validator ahli. Jumlah skor tertinggi dari skala Likert adalah 5 $\mathrm{P}=$ Persentase, $\mathrm{A}=$ Jumlah skor yang diperoleh, $\mathrm{B}=$ Jumlah skor maksimal. Kriteria persentase respons remaja sebagai berikut: $\mathrm{P}>80$ : Sangat
Baik, $70<$ P $<$ 80: Baik, $60<\mathrm{P}<70$ : Cukup Baik, $\mathrm{P}<60$ : Kurang Baik.

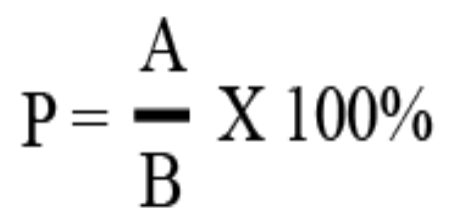

Gambar 1 Rumus.

\section{Bentuk Media Augmented Reality Animasi} Dewa Ruci

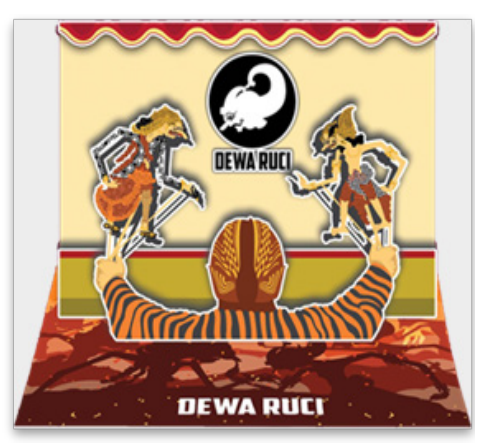

Gambar 2 Pop Up Card.

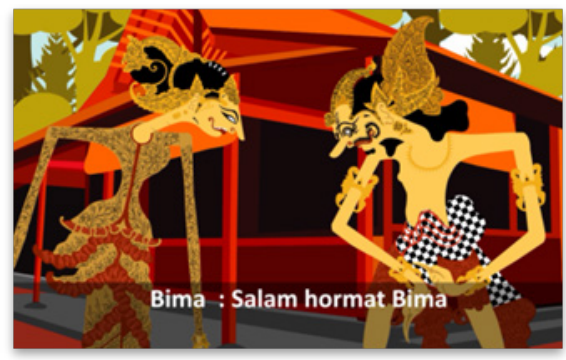

Gambar 3 Adegan Bima pamit kepada ibunya.

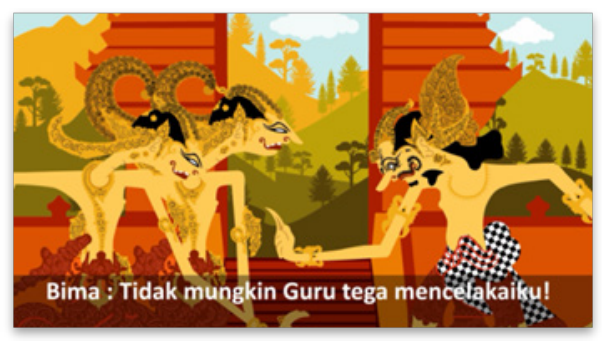

Gambar 4 Adegan Bima Pamit kepada Kedua Adiknya. 
Bentuk produk berupa pop up card yang berukuran A4 atau $210 \mathrm{~mm}$ x $297 \mathrm{~mm}$, yang terdapat marker logo lakon Dewa Ruci. Fungsi marker tersebut dapat di-scan melalui telepon pintar dengan menginstal aplikasi Vuforia. Jika kedua tahap tersebut sudah dilakukan, video animasi lakon Dewa Ruci dapat diakses atau dilihat.

Ada beberapa adegan yang dapat diterapkan dalam kehidupan sehari-hari. Gambar 3 adalah suatu ungkapan bahwa kewajiban seorang anak yang hendak meninggalkan rumah berpamitan kepada kedua orang tua terlebih dahulu. Gambar 4 adalah ketika kedua adik Bima menahan Bima untuk pergi, namun Bima tetap teguh pada pendiriannya. Bima adalah sosok ksatria yang berpikiran positif dalam menghadapi segala sesuatu.

\section{Kualitas Media Augmented Reality Animasi Dewa Ruci}

Kualitas media diukur berdasarkan validator ahli kegrafikaan. Hasil validasi kegrafikaan mendapat nilai sebesar 32. Nilai persentase yang diperoleh pada validasi pertama adalah sebesar $64 \%$ dengan mendapat nilai 43 . Nilai persentase yang diperoleh pada validasi kedua sebesar $86 \%$.

Pada teknik penyajian, desain pop up cardmen mendapatkan perhatian khusus. Desain sebelumnya menggunakan tempat pensil yang terbuat dari kardus. Kemudian setelah dilakukan revisi menjadi pop up card. Karena secara visual dan ergonomis pop up card dapat menarik perhatian kalangan remaja. Kualitas media juga diukur berdasarkan validator ahli materi. Hasil validasi materi mendapat nilai 37. Nilai persentase pada validasi pertama sebesar $74 \%$ dengan mendapat nilai 49 . Nilai persentase yang diperoleh pada validasi kedua sebesar 98\%. Dalam teknik penyajian, ada perubahan karakter dari tokoh Bima karena belum memenuhi kriteria lakon Dewa Ruci. Pada tahap revisi, Bima dalam scene awal hingga bertemu Dewa Ruci masih berambut gondrong, kemudian scene setelah menemui Dewa Ruci berambut pendek. Revisi tersebut dilakukan sebagai simbolisasi Bima telah mencapai atau mendapat ilmu kesempurnaan hidup.

\section{Keefektifan Media Augmented Reality Animasi Dewa Ruci}

Keefektifam media diukur dari uji coba pretest dan post test pada remaja. Remaja berjumlah 20 orang. Remaja mengisi kuesioner atau angket saat sebelum diberi produk untuk mengukur pengetahuan dan pemahaman remaja (pretest) dan sesudah (post test) diberi produk seberapa jauh tingkat pengetahuan dan pemahaman remaja.

Hasil angket pada pretest mendapatkan nilai 92. Nilai persentase yang diperoleh pada pretest sebesar $30 \%$. Pada post test didapatkan nilai 190. Nilai persentase yang diperoleh pada post test sebesar 63\%. Maka produk tersebut dapat dikatakan layak dan tidak perlu direvisi. Berikut tabel validasi remaja untuk menentukan hasil keefektifan produk.

\section{SIMPULAN}

Berdasarkan hasil penelitian yang telah dilakukan, simpulan dari penelitian pengembangan augmented reality lakon Dewa Ruci ini adalah sebagai berikut. Bentuk produk pop up card ditentukan melalui beberapa tahap analysis, design, implementation, dan maintenance. Tahap ini dilakukan dengan cara mengumpulkan data, memvisualkan gerak, uji coba produk, hingga tahap pengembangan lebih lanjut. 
Kualitas produk pop up card dinilai berdasarkan aspek kegrafikaan dalam menentukan tolok ukur dari produk yang dihasilkan harus memiliki nilai lebih dari segi pengemasan, desain, dan sebagainya. Selain itu, aspek materi menceritakan perjalanan Bima dari awal hingga akhir. Sikap dan perilaku dalam menanamkan pendidikan karakter yang dapat dijadikan suri teladan seperti saling menghormati, jujur, dan sopan santun dikemas dalam satu video animasi lakon Dewa Ruci yang berdurasi 10 menit 5 detik.

Keefektifan produk pop up card dinilai berdasarkan angket remaja, sebanyak 20 remaja di Perumahan Kota Baru Driyorejo. Hasil uji kualitas media aspek materi mendapatkan hasil 98\% dan pada post test mendapatkan hasil 63\%. Dari data angket tersebut dapat dikatakan produk ini layak dan tidak perlu direvisi.

\section{UCAPAN TERIMA KASIH}

Dr. Setyo Yanuartuti, M.Si.

Dr. I Nyoman Lodra, M.Si.

Dr. Autar Abdillah, M.Si.

Yohan Susilo, S.Pd., M.Pd.

Muhammad Rois Abidin, S.Pd., M.Pd.

Ki Surono Gondo Taruno

\section{KEPUSTAKAAN}

Sugiyono. (2013). Metode Penelitian Pendidikan: Pendekatan Kuantitatif, Kualitatif, dan R\&D. Bandung: Penerbit Alfabeta.

Haryani, Prita \& Triyono Joko. (2017). "Augmented Reality Sebagai Teknologi Interaktif dalam Pengenalan Benda Cagar Budaya Kepada Masyarakat", Jurnal SIMETRIS, 8(2):807-812.

Lestari, Puji. (2012). "Fenomena Kenakalan Remaja di Indonesia". Jurnal-Humanika, 12(1):1-23.

Mulyono, Sri. (1982). Wayang Asal-Usul Filsafat dan Masa Depannya. Jakarta: Penerbit PT Gunung Agung.
Nurgiyantoro, Burhan. (2011). "Wayang dan Pengembangan Karakter Bangsa", Jurnal Pendidikan Karakter, 1(1):18-34.

Prakosa, Gotot. (2010). Animasi Pengetahuan Dasar Film Animasi Indonesia. Jakarta: Penerbit Institut Kesenian Jakarta dan Yayasan Seni Visual Indonesia.

Pratiwi, Meliana, Surahman Sigit \& Annisarizki. (2019). "Cross Culture Generasi Milenial dalam Film My Generation", REKAM: Jurnal Fotografi, Televisi, dan Animasi, 15(1):13-32.

Ruslan, Arief. (2016). Animasi: Perkembangan dan Konsepnya. Bogor: Penerbit Ghalia Indonesia.

Sadewa, Ghalif Putra. (2019). "Membongkar Identitas dalam Film Wandu”, REKAM: Jurnal Fotografi, Televisi, dan Animasi, 15(1):71-82.

Saidi, Acep Iwan. (2017). Desain Media \& Kebudayaan. Bandung: Penerbit ITB.

Sejzi, Abdoli Abbas \& Bahru J. (2015). "Augmented Reality and Virtual Learning Environment". Journal of Applied Sciences Research, Universiti Teknologi Malaysia, 1-5.

Setiawan, Eko (2017). "Makna Filosofi Wayang Purwa dalam Lakon Dewa Ruci”, Jurnal Ilmu-Ilmu Ushuluddin, 5:399-418.

Suyitno, Imam. (2012). "Pengembangan Pendidikan Karakter dan Budaya Bangsa Berwawasan Kearifan Lokal", Jurnal Pendidikan Karakter, 1(1): 1-13. 
